\title{
Resolution of Pulmonary Embolism
}

\section{R. H. SECKER WALKER,* M.B., M.R.C.P. ; JUDY A. JACKSON, †; JAN GOODWIN, † S.R.N.}

\begin{abstract}
Cummary: To assess restoration of pulmonary perfusion $\checkmark$ after pulmonary embolism serial lung scans were carried out on 74 patients. Of these, one-third showed almost complete recovery, one-third improved, and the remainder either failed to improve or became worse. Perfusion was most rapidly restored in the first few days after the embolus and more slowly during the next two to three weeks.

Untreated patients improved less often and had more new defects in perfusion than patients treated with anticoagulant therapy, no difference occurring in either the amount of improvement or in the rate of recovery of perfusion between patients treated with different anticoagulant regimens. There was evidence of further pulmonary emboli in $35 \%$ of treated patients, $82 \%$ of these occurring within two weeks of the initial embolus. Patients with defects in perfusion greater than $30 \%$ showed considerable improvement but recovered less well than those with smaller defects.
\end{abstract}

\section{Introduction}

Pulmonary emboli can be shown by pulmonary angiography (Williams et al., 1963; Stein et al., 1967), and the defects in perfusion that they cause are readily and safely shown by lung scanning (Quinn et al., 1964; Wagner et al., 1964). Their resolution can also be studied by serial pulmonary angiography (Sautter et al., 1964; Fred et al., 1966), but serial lung scanning offers a safer way of studying the restoration of pulmonary perfusion (Poe et al., 1967; Rosenthal, 1968). Furthermore, lung scanning allows a measure of quantitation that is not possible with angiography (Tow and Wagner, 1967; Murphy and Bulloch, 1968; Winebright et al., 1970) and makes comparisons between different methods of treatment a practical proposition.

This paper describes the results of serial lung scanning in 74 patients with pulmonary embolism seen at University College Hospital during 1967-9.

\section{Patients and Methods}

The patients selected for this study had a clinical diagnosis of pulmonary embolism based on the history and physical signs, supported by electrocardiographic, radiographic, or lung-scan evidence. In three patients the diagnosis was confirmed by pulmonary angiography and in one at necropsy. As they were admitted under several different physicians and surgeons their treatment varied considerably. A few received no anticoagulant treatment initially, either because they suffered from a potentially haemorrhagic condition or because their first episode was not recognized as a pulmonary embolus until another occurred. The other patients were treated with intravenous heparin alone for 10 to 21 days, or with intravenous heparin for two to three days followed by oral anticoagulation (with either phenindione or warfarin), or just with oral anticoagulants alone.

The lung scans were carried out as described previously (Secker Walker, 1968) using $1.5-2 \mathrm{mCi}$ of technetium $-99^{\mathrm{m}}$ labelled macroaggregated human serum albumin. The scans

* Lecturer in Medicine.

t Laboratory Technician.

¥ Research Assistant.

Medical Unit, University College Hospital Medical School, London W.C.1. were made with a Picker Magnascanner III, producing both colour dot scans and photoscans simultaneously. Anterior and posterior views were done whenever possible.

A semiquantitative method of assessment was used to compare one lung scan with another, based on the colour dot scans. The Picker Magnascanner has an eight-colour ribbon, each colour representing a $12.5 \%$ fraction of the maximum count rate. Each lung was divided into upper, middle, and lower zones on both anterior and posterior scans-that is, a total of 12 zones. Each zone was then scored from 0 to 4; no activity scoring 0 , a normal pattern scoring 4 , and the defects in perfusion scoring according to their size and the level of activity, which was determined from the colour of the dots present. The maximum possible score in a normal subject was therefore 48 $(100 \%)$. Defects in perfusion were expressed as a percentage of the maximum score. When the lung scans were scored by the same observer on a second occasion the maximum error was $7 \%$. In addition, this method of scoring was applied to 12 normal lung scans and 56 lung scans of patients with carcinoma of the bronchus in which the colour dots had previously been counted by hand to assess the relative perfusion of each lung (Secker Walker and Provan, 1969). There was a close correlation between these two methods of estimating the relative amount of radioactivity in each lung $(r=0.986$, $\mathrm{P}<0.001)$.

The lung-scan scores of the 12 healthy individuals ranged from 89.5 to $100 \%$, with a mean of $96.8 \% \pm 1.05 \%$ (S.E. of mean), and the mean difference in score between repeat scans in five of these individuals was $2.5 \%$.

The improvement in the serial scans has been expressed as the change in score since the first scan, and the degree of recovery as the percentage improvement of the defect. A lung scan was regarded as normal when its score reached the normal range, even though minor defects might still be visible. A lung scan was said to have improved if its score increased by more than $25 \%$, but did not reach the normal range. Any change less than this has been treated as no change.

None of these patients had pulmonary angiograms or haemodynamic studies during the acute stage of their illness (though three had angiograms later), so that the size of the defects cannot be directly compared with the degree of obstruction of the pulmonary vasculature.

\section{Results}

The age distribution of the 74 patients, the interval between the onset of symptoms and the first lung scan, and some aetiological factors are shown in Table I. Their presenting symptoms and the electrocardiographic and chest radiographic findings are shown in Table II. Two hundred

\begin{tabular}{|c|c|c|c|c|}
\hline Age & $\begin{array}{l}\text { No. of } \\
\text { Patients }\end{array}$ & $\begin{array}{r}\text { Interva } \\
\text { Symp } \\
\text { Pulmona } \\
\text { and }\end{array}$ & $\begin{array}{l}1 \text { between } \\
\text { toms of } \\
\text { ry Embolus } \\
\text { Scan }\end{array}$ & Aetiological Factors \\
\hline $\begin{array}{l}20-29 \\
30-39 \\
40-49 \\
50-59 \\
60-69 \\
70-79 \\
80-89\end{array}$ & $\begin{array}{r}7(9.5 \%) \\
7(9.5 \%) \\
8(10.8 \%) \\
25(33.8 \%) \\
17(22.9 \%) \\
8(10.8 \%) \\
2(2.7 \%)\end{array}$ & $\begin{array}{l}\text { C1 day } \\
2-4 \text { days } \\
5-7 \text { days } \\
8-14 \text { days } \\
>14 \text { days } \\
\text { Unknown }\end{array}$ & $\begin{array}{c}23(31 \cdot 0 \%) \\
11(15 \cdot 0 \%) \\
15(20 \cdot 3 \%) \\
9(12 \cdot 0 \%) \\
13(17 \cdot 7 \%) \\
3(4 \cdot 0 \%)\end{array}$ & $\begin{array}{l}\text { Postoperative period } 27(36.5 \%) \\
\text { Deep vein thrombosis } 20(27.0 \%) \\
\text { Previous pulmonary } \\
\text { embolism or deep } \\
\text { vein thrombosis } 14(19.0 \%) \\
\text { Hypertension, ischaemic } \\
\quad \text { heart disease, or } \\
\text { chronic rheumatic } \\
\text { heart disease } \\
\text { On a contraceptive pill } 19(25.5 \%) \\
9(12.0 \%)\end{array}$ \\
\hline
\end{tabular}


TABLE II.-Symptoms and Electrocardiographic and Chest Radiographic Findings in 74 Patients with Pulmonary Embolism

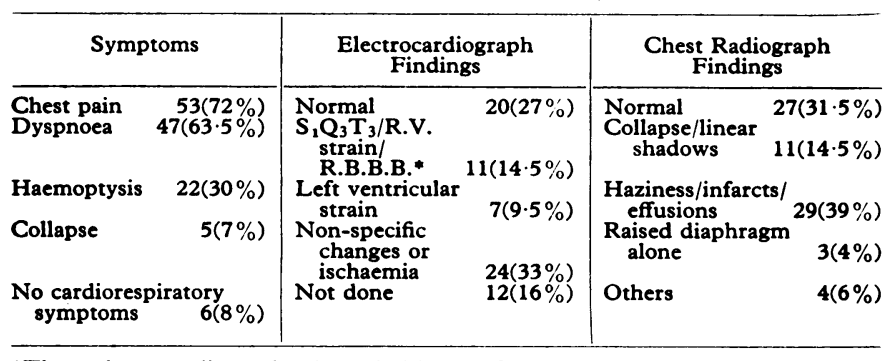

-These electrocardiographs showed either an $S_{1} Q_{3} T_{3}$ pattern, or evidence of right ventricular strain or right bundle-branch block.

TABLE III.-Number of Serial Scans and New Defects seen on Serial Scanning

\begin{tabular}{|c|c|c|c|c|c|c|}
\hline & \multicolumn{5}{|c|}{ No. of Scans } & \multirow{2}{*}{ Tota } \\
\hline & 2 & 3 & 4 & 5 & $6+$ & \\
\hline $\begin{array}{l}\text { No. of patients } \\
\text { No. of patients with new defects } \\
\text { No. of new defects } \\
\text { No. of patients with new defects and an } \\
\text { overall reduction in lung-scan score }\end{array}$ & $\begin{array}{l}43 \\
29 \\
38 \\
10\end{array}$ & $\begin{array}{r}23 \\
6 \\
8\end{array}$ & $\begin{array}{l}4 \\
1 \\
1\end{array}$ & $\begin{array}{l}2 \\
1 \\
1\end{array}$ & $\begin{array}{l}2 \\
1 \\
1\end{array}$ & $\begin{array}{l}74 \\
38 \\
49 \\
15\end{array}$ \\
\hline
\end{tabular}

TABle IV.-Extent of Defect in Final Lung Scan in 74 Patients with Pulmonary Embolism

\begin{tabular}{|c|c|c|c|c|c|}
\hline \multirow[b]{2}{*}{$\begin{array}{l}\text { Range of } \\
\text { Defect. \% } \\
\text { Maximum } \\
\text { Score }\end{array}$} & \multirow[b]{2}{*}{$\begin{array}{c}\text { No. of } \\
\text { Patients }\end{array}$} & \multicolumn{4}{|c|}{$\begin{array}{c}\text { Mean Size of Defect in Each Group as \% Maximum } \\
\text { Score } \pm \text { S.E. of Mean }\end{array}$} \\
\hline & & $\begin{array}{l}\text { First } \\
\text { Scan }\end{array}$ & $\begin{array}{l}\text { Final } \\
\text { Scan }\end{array}$ & $\begin{array}{c}\text { Final Scan } \\
\text { More Than } 6 \\
\text { Weeks After } \\
\text { Embolus* }\end{array}$ & $\begin{array}{c}\text { Final Scan } \\
\text { More Than } 6 \\
\text { Weeks After } \\
\text { Embolus } \\
\text { Excluding } 6 \\
\text { Patients with } \\
\text { Chronic } \\
\text { Disease*t }\end{array}$ \\
\hline $\begin{array}{l}0-15 \\
16-30 \\
31-45 \\
>45\end{array}$ & $\begin{array}{l}13 \\
26 \\
18 \\
17\end{array}$ & $\begin{array}{l}12 \cdot 0 \pm 0 \cdot 9 \\
22 \cdot 3 \pm 0 \cdot 8 \\
37 \cdot 3 \pm 2 \cdot 7 \\
56 \cdot 0 \pm 2 \cdot 1\end{array}$ & $\begin{array}{l}10 \cdot 1 \pm 1 \cdot 7 \\
16 \cdot 4 \pm 2 \cdot 0 \\
21 \cdot 5 \pm 2 \cdot 7 \\
30 \cdot 1 \pm 3 \cdot 7\end{array}$ & $\begin{array}{l}10 \cdot 1 \pm 2 \cdot 4(8) \\
12 \cdot 4 \pm 2 \cdot 1(10) \\
20 \cdot 3 \pm 4 \cdot 7(8) \\
27 \cdot 2 \pm 5 \cdot 7(9)\end{array}$ & $\begin{array}{r}10 \cdot 1 \pm 2 \cdot 4(8) \\
9 \cdot 8 \pm 1 \cdot 1(8) \\
17 \cdot 2 \pm 4 \cdot 1(7) \\
20 \cdot 4 \pm 1 \cdot 2(6)\end{array}$ \\
\hline
\end{tabular}

* The numbers in parentheses are the number of patients in each group scanned

after six weeks. and emphysema; 1 chronic rheumatic heart disease; 1 septic embolus leading to lung abscess; 1 bronchial asthma.

lung scans were carried out on these patients, and the number of follow-up scans is shown in Table III. Of 269 defects shown in the initial scans 67 were in the upper lobes, 74 in the middle lobes and lingulae, and 128 in the lower lobes. Each lung was involved almost equally.

The number of patients with new defects in their follow-up scans is also shown in Table III. Forty-nine new defects were seen in 33 patients, seven patients had two or more new defects, and five patients had new defects in two of their follow-up scans. The patients have been grouped according to the size of their initial defect in perfusion (Table IV). Their final defect in perfusion-that is, the defect on their last scan, which does not necessarily indicate how much recovery may have eventually occurred-is also shown, together with the final defect in patients scanned six weeks or more after their first scan.

Twenty-nine patients without chronic cardiorespiratory disease had follow-up scans six weeks or more after their pulmonary embolus. The average final defect in 13 patients whose initial defect was greater than $30 \%$ was $18.7 \% \pm 2 \cdot 2$ (S.E. of mean), which is significantly greater than the average final defect $(9.9 \% \pm 1.3$ (S.E. of mean)) in the 16 patients with initial defects less than $30 \%(t=3.55, \mathrm{P}<0.002)$.

Twenty-four patients $(32.5 \%)$ recovered sufficiently to achieve scores within the normal range, though only two scans became completely normal. Another 24 patients showed improvement in their scans, while the scans in the other 26 patients $(35 \%)$ showed no appreciable change or became worse (10 of these were not on anticoagulant treatment).

Though most of the patients $(8 / 11)$ who had three or more scans during the first month after their embolus showed a progressive improvement in the pattern of perfusion, the degree of recovery in any individual varied greatly-from complete resolution to the presence of new defects. In Fig. 1 the patients have been grouped by the time interval between their first and subsequent scans, and the degree of recovery has been plotted against the mean time to follow-up scan in each group. The average degree of recovery during the first four weeks in patients receiving anticoagulant therapy, who had no evidence of further embolic episodes, was $40 \%$ of the initial defect, and was as good within four days of the

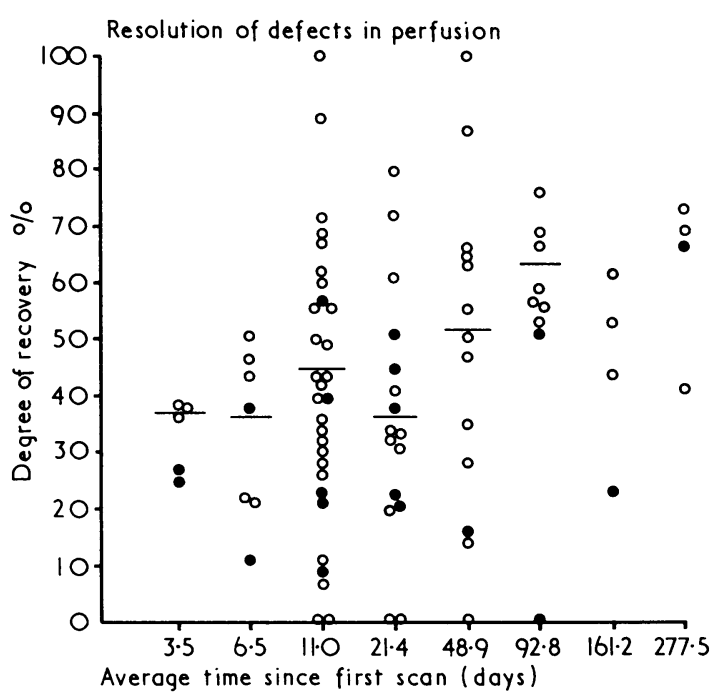

FIG. 1.- Patients on anticoagulant therapy have been grouped by the average time to each follow-up scan between 1 and 4 days, 5 and 7 days, 8 and 14 days, 15 and 28 days, 1 and 2 months, 3 and 4 months, 5 and 6 months, and more than 6 months. Open circles represent patients who showed no evidence of new defects while on treatment, and closed circles patients who did show evidence of new defects. Horizontal bars represent the mean who did show evidence of new defects. Horizontal bars represent the mean degree of recovery of patients with no evidence of new defects. Patients
whose lung scans became worse than their first scan are not included.

TABle V.-Influence of Age, Size of Defect, Treatment, Sex, and Postoperative Status on the Improvement in Perfusion seen in each Patient's Final Scan

\begin{tabular}{|c|c|c|c|c|c|c|c|c|c|c|c|c|}
\hline \multirow[b]{2}{*}{ Final Scan Score } & \multicolumn{2}{|c|}{ Age } & \multicolumn{2}{|c|}{ Size of Defect } & \multicolumn{4}{|c|}{ Treatment* } & \multicolumn{2}{|c|}{ Sex } & \multicolumn{2}{|c|}{ Status } \\
\hline & $<60$ & $>60$ & $<30 \%$ & $\$ 30 \%$ & None & $\mathbf{H}$ & $\mathrm{O}$ & $\mathrm{H}+\mathrm{O}$ & Male & Female & $\begin{array}{l}\text { Postoperative } \\
3 \text { Weeks }\end{array}$ & $\begin{array}{c}\text { No } \\
\text { Preceding } \\
\text { Operation }\end{array}$ \\
\hline Normal range & $19(40 \%)$ & $5(19 \%)$ & $19(49 \%)$ & $5(14 \%)$ & $1(7 \cdot 5 \%)$ & $7(39 \%)$ & $6(46 \%)$ & $10(31 \%)$ & $10(28 \%)$ & $14(37 \%)$ & $12(43 \%)$ & $12(26 \%)$ \\
\hline Improved .. & $14(30 \%)$ & $10(37 \%)$ & $4(10 \%)$ & $20(57 \%)$ & $2(15 \%)$ & $7(39 \%)$ & $4(31 \%)$ & $12(38 \%)$ & $12(33 \%)$ & $12(31.5 \%)$ & $9(32 \%)$ & $15(33 \%)$ \\
\hline No change or worse & $14(30 \%)$ & $12(44 \%)$ & $16(41 \%)$ & $10(29 \%)$ & $10(77 \cdot 5 \%)$ & $4(22 \%)$ & $3(23 \%)$ & $10(31 \%)$ & $14(39 \%)$ & $12(31 \cdot 5 \%)$ & $7(25 \%)$ & $19(41 \%)$ \\
\hline$x^{2}$ & \multicolumn{2}{|c|}{3.86} & \multicolumn{2}{|c|}{$20 \cdot 1$} & \multicolumn{4}{|c|}{ Not valid } & \multicolumn{2}{|c|}{0.76} & \multicolumn{2}{|c|}{$2 \cdot 83$} \\
\hline D.F. & \multicolumn{2}{|c|}{2} & \multirow{2}{*}{\multicolumn{2}{|c|}{0.005}} & & & & & \multicolumn{2}{|c|}{2} & \multicolumn{2}{|l|}{2} \\
\hline . $\quad$. & \multicolumn{2}{|c|}{ N.S. } & & & & & & & \multicolumn{2}{|c|}{ N.S. } & \multicolumn{2}{|c|}{ N.S. } \\
\hline
\end{tabular}

2 patients are included twice as they were initially untreated. One was then treated by heparin alone and the other by phenindione alone. 2 patients are included twice as they were initially untreated. One was then treated by heparin alone and the other by phenindione alone.
$\mathrm{H}=$ Intravenous heparin for $10-21$ days. $\mathrm{O}=$ Oral anticoagulants with either phenindione or warfarin. $\mathrm{H}+\mathrm{O}=\mathrm{Intravenous}$ heparin for $2-4$ days followed by oral anti-
coagulation. D.F. = Degrees of freedom. N.S. = Not significant $(\mathrm{P}>0.05)$. 


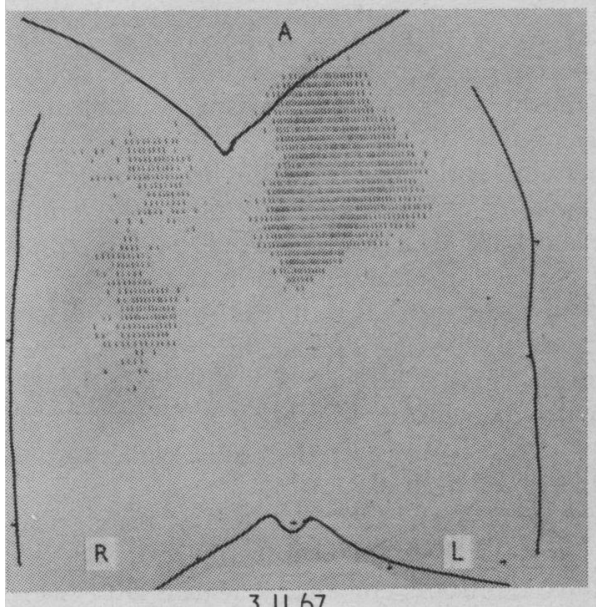

3.11 .67

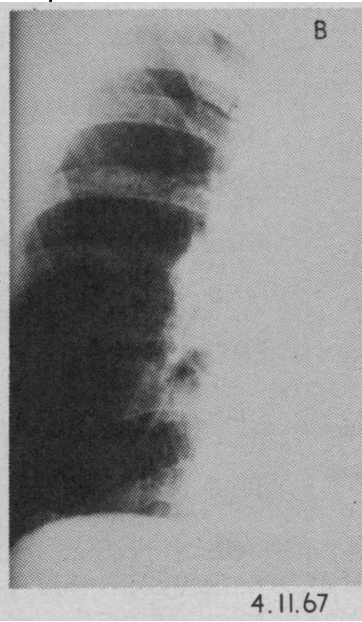

B

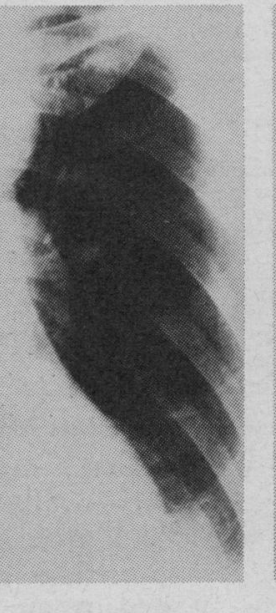

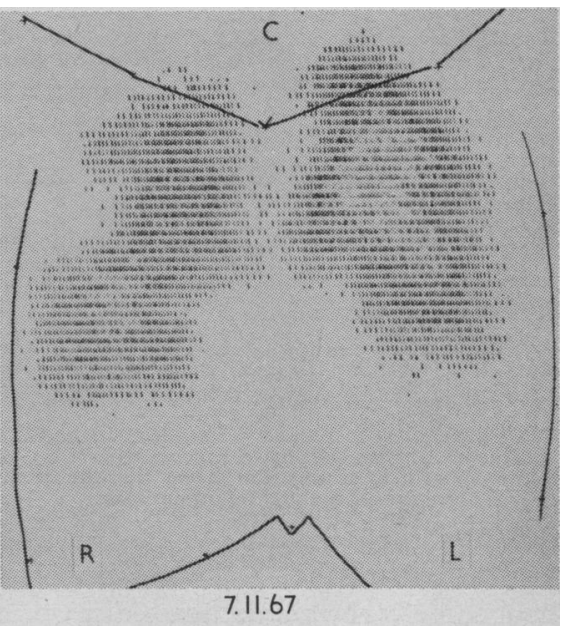

Fig. 2.-A man aged 70 collapsed with severe dyspnoea 14 days after a prostatectomy. He was treated with intravenous heparin followed by warfarin and made an excellent recovery. (A) Anterior lung scan, carried out the same day, showing very little perfusion of the right lung, absent perfusion of the left lower lobe and lingula, and irregularities in perfusion in the rest of the left upper lobe. (B) Chest radiograph showing clear lung fields. (C) Anterior lung lower lobe and lingula, and irregularities in perfens in both lungs. Two more scans, at 10 days and three months, showed a return to normal on the left, but a defect remained on the right.

embolus as it was within four weeks. During the second month the trend was to further slow improvement, the average degree of recovery being $50 \%$ of the initial defect, which rose to $60 \%$ during the third and fourth months. Little further improvement was seen after this.

Twenty-two $(35 \%)$ of the 63 patients who had follow-up scans while on treatment showed new defects in perfusion which were probably due to further emboli. All were seen within seven weeks of the initial episode and 18 within one month. Fresh emboli occurred in nine of the untreated patients, seven within two weeks and the other two within five weeks.

The effects of several factors that might influence the resolution of pulmonary emboli are shown in Table V. Though fewer patients aged 60 or more achieved lung-scan scores within the normal range compared with patients under this age, these differences are not statistically significant $\left(\chi^{2}=3.86\right.$, D.F. 2, P>0.05).

The size of the initial defect does affect the outcome. Only $14 \%$ of the patients with defects $30 \%$ or greater achieved lung scan scores within the normal range, whereas $49 \%$ of those with smaller defects did so. These differences are statistically significant $\left(\chi^{2}=20.1\right.$, D.F. $\left.2, P<0.005\right)$. The figures shown in Table $\mathrm{V}$ for the various treatment groups are too small to allow a valid $\chi^{2}$ test, so that each treatment group has been compared with the untreated group separately. The comparisons have been made between improvement in the first follow-up lung scan-that is, an increase in score of more than $25 \%$-and no improvement or worsening of the scan, and also by comparing the number of new defects seen in the first follow-up scan (Table VI). Improvement occurs significantly more often in each treated group compared with the untreated group.

In addition, significantly fewer defects are seen in the patients treated with heparin followed by oral anticoagulants and in those treated with oral anticoagulants alone. The difference between patients treated with heparin alone and the untreated patients is not significant (Table VI), but the patients treated with heparin had fewer large new defects so that their overall lung-scan scores improved more often. There is no significant difference between the three treatment groups with respect either to improvement in their lung scans or to the appearance of new defects.

A larger proportion of the lung scans of patients having an embolus within three weeks of an operation improved or reached a normal score than did those who had no operation in the preceding three months, but the differences are not significant. No difference in recovery was observed when one sex was compared with the other. Five patients with severe cardiorespiratory disease failed to show improvement in their lung scans.

Fig. 2 shows an example of rapid improvement in perfusion after pulmonary embolism in a man aged 70, while Fig. 3 shows little overall improvement in a patient aged 61 who

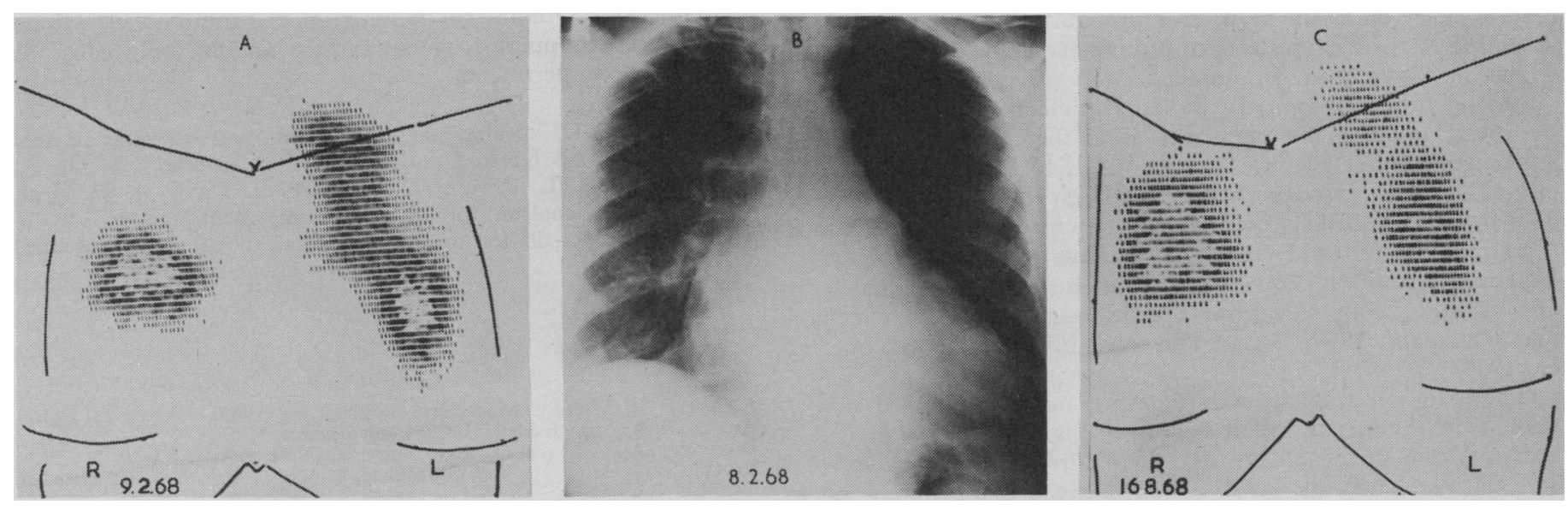

FIG. 3.-A married woman aged 61 suffered from chronic rheumatic heart disease with mitral incompetence for many years. Attacks of dyspnoea with cyanosis led to a diagnosis of pulmonary embolism, which was supported by the lung scan. She was treated by intravenous heparin initially, followed by warfarin till her death 14 months later. (A) Anterior lung scan showing defects in perfusion in both lungs. (B) Chest radiograph the previous day showing cardiomegaly but clear lung fields. (C) Anterior lung scan six months later, showing some improvement in the right lung but worsening of the left. 
TABLE VI.-Effect of Treatment on Changes Seen at the First Follow-up Lung Scan in 74 Patients with Pulmonary Embolism*

\begin{tabular}{|c|c|c|c|c|c|c|}
\hline \multicolumn{3}{|c|}{ Lung Scan } & $\begin{array}{c}\text { No } \\
\text { Treatment }\end{array}$ & Heparin & $\begin{array}{l}\text { Oral Anti- } \\
\text { coagulants }\end{array}$ & \begin{tabular}{|l} 
Heparin + \\
Oral Anti- \\
coagulants
\end{tabular} \\
\hline $\begin{array}{l}\text { Improvement } \dagger \\
\text { No change or worse }\end{array}$ & $\because$ & $\because$ & $\begin{array}{r}3 \\
10\end{array}$ & $\begin{array}{c}14 \\
4 \\
x^{2}=9 \cdot 1 \\
P<0.005\end{array}$ & $\begin{array}{c}10 \\
3 \\
x^{2}=7.5 \\
P<0.01\end{array}$ & $\begin{array}{c}22 \\
10 \\
x^{2}=7.8 \\
P<0.01\end{array}$ \\
\hline $\begin{array}{l}\text { No new defects } \\
\text { New defects }\end{array}$ & & $\therefore$ & $\begin{array}{l}4 \\
9\end{array}$ & $\begin{array}{c}11 \\
7 \\
x^{2}=2.8 \\
P<0.1\end{array}$ & $\begin{array}{c}10 \\
x^{2}=5.6 \\
P<0.025\end{array}$ & $\begin{array}{c}22 \\
10 \\
x^{2}=5.5 \\
P<0.025\end{array}$ \\
\hline
\end{tabular}

- Two patients are included twice as they both had follow-up scans while receiving no

treatment and after starting treatment.
timprovement in a lung scan means that the defect had decreased by more than $25 \%$ by the time of the first follow-up scan.

had chronic rheumatic heart disease, complicated by pulmonary embolism.

\section{Discussion}

The diagnosis of pulmonary embolism in these patients rests on the clinical, electrocardiographic, radiographic, and lung-scan evidence. In only four patients was the diagnosis confirmed by other means. Pulmonary angiography, however, which is regarded as the diagnostically definitive procedure (Raphael, 1970), gives rise, experimentally, to more false-positive diagnoses and fails to show pulmonary emboli about as often as does lung scanning (Moser et al., 1969). Furthermore, scanning is superior to angiography in demonstrating defects in perfusion due to small emboli (U.C.L.A. Interdepartmental Conference, 1967). Defects in perfusion are common in patients with chronic bronchitis and emphysema (LopezMajano et al., 1966) and may be misleading in elderly patients (Secker Walker, 1969). Several of our patients were excluded for this reason.

A variety of semiquantitative methods have been used to assess the resolution of pulmonary embolism (Tow and Wagner, 1967; Murphy and Bulloch, 1968; Winebright et al., 1970), but to determine the presence and size of defects in perfusion a subjective comparison is made with the normal pattern of perfusion so that at present no truly quantitative measure of their magnitude is possible. The method of scoring lung scans is relatively simple and reproducible, and the good correlation between the two methods in determining the relative quantity of radioactivity in each lung allows reasonable confidence in the semiquantitative method.

Just over one-third of the patients having treatment $(35 \%)$ had new defects in perfusion in their follow-up scans. Some patients had symptoms suggesting a further embolus shortly before their follow-up scan, and probably most new defects were due to further episodes of pulmonary embolism, some of which may have been symptomless.

Among the untreated patients defects in perfusion improved at much the same rate as in the patients receiving anticoagulant therapy, but because they had further and often larger embolic episodes their overall improvement was less. The fewer new defects occurring in patients on anticoagulant therapy compared with untreated patients supports other evidence that anticoagulants reduce the incidence of clinically and pathologically recognizable pulmonary embolism (Sevitt and Gallagher, 1959; Barritt and Jordan, 1960; Bottomley et al., 1964).

The patients treated with heparin alone had more new defects in their first follow-up scans than the other treated patients, though these were usually small so that their overall improvement was as good. Their anticoagulation may not always have been adequate, but we would agree with Browse et al. (1969) "that heparin is not as effective in preventing recurrent embolism as many claim." The similarity in the improvement seen in the three treatment groups and in the few untreated patients who had no new emboli, suggests that the restoration of perfusion depends more on mechanical factors, physiological mechanisms of fibrinolysis, and recanalization than on any (hypothetical) action of the anticoagulants themselves. The benefit of anticoagulation lies in its effect on the leg or pelvic veins-that is, in preventing new venous thromboses-and in stopping the extension of existing ones rather than speeding the resolution of emboli in the lungs.

Perfusion is restored most rapidly in the first few days after the embolus, more slowly during the next two to three weeks, and even more slowly after this. This time scale matches that seen in the dissolution of emboli studied by pulmonary angiography both in man (Fred et al., 1966) and in dogs (Allison et al., 1960; Dalen et al., 1966).

The amount of recovery seen in the patients with initial defects greater than $45 \%$ is of considerable interest. The six patients in this group, without chronic disease, who were followed-up for more than six weeks had a mean final defect of about $20 \%$. This obvious improvement in patients with massive pulmonary embolism (which is not as impressive as that reported by Rosenthal (1968)) is comparable to the improvement with streptokinase (Hirsh et al., 1968; Miller et al., 1969) though perhaps spread over a longer interval.

Increasing age was no bar to considerable improvement in perfusion, nor were premenopausal women less able to dispose of their emboli than postmenopausal women or men of the same age. The presence of chronic rheumatic heart disease, chronic bronchitis and emphysema, and a septic embolus leading to a lung abscess were all associated with reduced recovery.

Failure to improve during the first month after an embolus may be due to associated chronic disease (Chait et al., 1967; Murphy and Bulloch, 1968), but also to recurrent pulmonary embolism or, more rarely, to failure of resolution of the embolus. Recurent pulmonary emboli produce a changing pattern of perfusion that is almost characteristic, but when an embolus fails to resolve the pattern remains the same.

Evidence of fresh emboli in patients on anticoagulant therapy was seen up to seven weeks after the initial embolus. Many of these were symptomless, so that serial lung scans will sometimes suggest the need both for further investigation of the leg veins and for surgical measures to prevent yet more pulmonary emboli. There was little to choose between the three anticoagulant regimens so far as improvement in perfusion was concerned, but oral anticoagulants should probably be continued for at least two months-that is, beyond the time when recurrent episodes are likely to happen.

There have been several reports of the successful removal of pulmonary emboli weeks or months after they occurred (Snyder et al., 1963; Brock et al., 1967; Nash et al., 1968). Should a large defect persist and embolectomy be considered undoubtedly pulmonary angiography should be done beforehand, for pulmonary emboli are not the only cause of large defects in perfusion.

We are grateful to the many physicians and surgeons at this hospital who have referred patients for lung scanning; to Dr. A. Hollman, Mr. J. L. Provan, Dr. E. J. Ross, Dr. P. J. D. Heaf, and Dr. H. Nicholson for their encouragement and advice; to Mrs. M. MacDonald for technical assistance; and to the Medical School Photographic Department for the illustrations.

\section{REFERENCES}

Allison, P. R., Dunnill, M. S., and Marshall, R. (1960). Thorax, 15, 273. Barritt, D. W., and Jordan, S. C. (1960). Lancet, 1, 1309.

Bottomley, J. E., Lloyd, O., and Chalmers, D. G. (1964). Lancet, 2, 835. 4, 598. Nabil, H., and Gibson, R. V. (1967). British Medical fournal,

Browse, N. L., Thomas, M. L., Solan, M. J., and Young, A. E. (1969). British Medical Fournal, 3, 382 .

Chait, A., Summers, D., Krasnow, N., and Wechsler, B. M. (1967). American fournal of Roentgenology, Radium Therapy, and Nuclear Medicine,

Dalen, J. E. et al. (1966). American Heart fournal, 72, 509. 
Fred, H. L., Axelrad, M. A., Lewis, J. M., and Alexander, J. K. (1966). Fournal of the American Medical Association, 196, 1137.

Hirsh, J., Hale, G. S., McDonald, I. G., McCarthy, R. A., and Pitt, A. (1968). British Medical fournal, 4, 729.

Lopez-Majano, V., Tow, D. E., and Wagner, H. N. (1966). Fournal of the American Medical Association, 197, 81 .

Miller, G. A. H., Gibson, R. V., Honey, M., and Sutton, G. C. (1969). British Medical fournal, 1, 812.

Moser, K. M., et al. (1969). Circulation, 39, 663.

Murphy, M. L., and Bulloch, R. T. (1968). Circulation, 38, 1116.

Nash, E. S., Shapiro, S., Landau, A., and Barnard, C. N. (1968). Thorax, 23, 121 .

Poe, N. D., Swanson, L.A., Dore, E. K., and Taplin, G. V. (1967). American Heart fournal, 73, 582.

Quinn, J. L., Whitley, J. E., Hudspeth, A. S., and Prichard, R. W. (1964). Radiology, 82, 315 .

Raphael, M. J. (1970). British fournal of Hospital Medicine, 3, 377.

Rosenthal, L. (1968). Fournal of the Canadian Association of Radiologists, $19,135$.
Sautter, R. D., Fletcher, F. W., Emanuel, D. A., Lawton, B. R., and Olsen, T. G. (1964). Fournal of the American Medical Association, 189, 948.

Secker Walker, R. H. (1968). British Medical fournal, 2, 206.

Secker Walker, R. H. (1969). Geriatrics, 24, 81.

Secker Walker, R. H. and Provan, J. L. (1969). British Medical fournal, 3, 327.

Sevitt, S., and Gallagher, N. (1959). Lancet, 2, 981.

Snyder, W. A., Kent, D. C., and Baisch, B. F. (1963). Fournal of Thoracic and Cardiovascular Surgery, 45, 482.

Stein, P. D., et al. (1967). American Heart Fournal, 73, 731.

Tow, D. E., and Wagner, H. N. (1967). New England fournal of Medicine, 276, 1053.

U.C.L.A. Interdepartmental Conference (1967). Annals of Internal Medicine, 67, 1059.

Wagner, H. N., Sabiston, D. C., McAfee, J. G., Tow, D., and Stern, H. S. (1964). New England Fournal of Medicine, 271, 377.

Williams, J. R., Wilcox, C., Andrews, G. J., and Burns, R. R. (1963). Fournal of the American Medical Association, 184, 473.

Winebright, J. W., Gerdes, A. J., and Nelp, W. B. (1970). Archives of Internal Medicine, 125, 241.

\section{Control of Heparin Therapy}

\section{W. R. PITNEY,* M.D., F.R.A.C.P. ; J. E. PETTIT, $†$ M.B., CH.B. ; LYN ARMSTRONG, $\ddagger$ F.I.M.L.T.}

\begin{abstract}
Gummary: Heparin therapy in 114 patients was controlled by daily blood tests-the whole blood coagulation time, kaolin-activated partial thromboplastin time of plasma, and plasma heparin assay. Bleeding episodes occurred in 7 out of 92 patients $(7.6 \%)$ who had normal haemostatic mechanisms before therapy and in 11 out of 22 patients $(50 \%)$ with defective haemostasis, mostly due to intravascular coagulation or renal failure. The dose of heparin ranged from 20,000 to 60,000 units in each 24-hour period. In some patients bleeding was related to overdosage, but in others the laboratory tests indicated satisfactory or suboptimal dosage at the time of bleeding. Though there were positive correlations between the results of the three tests, these were not close, and no one test was preferable. Hence laboratory control of heparin therapy is unsatisfactory and patients may bleed despite careful control of the dose by all three methods.
\end{abstract}

\section{Introduction}

Heparin is a powerful anticoagulant widely used and of established value in the management of thromboembolic disease. It has also been used recently in the treatment of disseminated intravascular coagulation, microangiopathic haemolytic anaemia, haemolytic-uraemic syndrome, impending renal homograft rejection, and some types of renal failure (Brain et al., 1968; Kincaid-Smith et al., 1968). Haemostasis is of ten impaired in these latter disorders, most commonly owing to thrombocytopenia or platelet dysfunction, and heparin therapy would be expected to be associated with a considerable risk of bleeding in such patients. The extent of this risk, however, has not been defined but would presumably be related to dosage and to adequacy of laboratory control. Even when heparin is used in the treatment of thromboembolism there are conflicting reports on the incidence of bleeding episodes. Kernohan and Todd (1966) reported 12 bleeding episodes in 82 treatments, Jick et al. (1968) 23 episodes in 97 treatments, while O'Sullivan et al. (1968), using strict laboratory control of therapy, experienced only four bleeding episodes in 100 treatments; in two of these the patients were being treated concurrently with oral anticoagulants.

Methods available for the control of heparin therapy include the whole-blood coagulation time, kaolin-activated partial thromboplastin time of plasma (Spector and Corn,

\footnotetext{
Reader in Haematology, Royal Postgraduate Medical School, London

† Senior Registrar in Haematology, Hammersmith Hospital, London W.12. $\ddagger$ Research Technician.
}

1967), and measurement of plasma heparin concentration by protamine titration (Dacie and Lewis, 1968). In this paper the results of these three tests in a group of patients receiving heparin are compared. Since one aim of such tests is to indicate the presence of overdosage, bleeding episodes, when they occurred, were analysed with respect to the laboratory findings at the time bleeding began.

\section{Patients and Methods}

Multiple tests were performed on 229 occasions on 87 patients who were receiving heparin by continuous infusion. In addition, therapy was controlled by either the whole-blood coagulation time or the plasma heparin assay in another 27 patients, giving data on 114 patients in all. Most patients were treated by drip infusion, the heparin dose for a 12-hour period being added to 1 litre of saline or dextrose-saline. Some patients were treated by constant infusion pump, the 24-hour dose being added to saline in a syringe preset to administer $2 \mathrm{ml}$. of fluid per hour. Blood was drawn daily for tests of heparin control and the dose adjusted on the basis of the results obtained. Bleeding episodes have been analysed only if tests were performed on the day concerned.

Tests for Blood Heparin Activity.-Whole-blood coagulation times were estimated by the Lee-White method at $37^{\circ} \mathrm{C}$., a portable water bath at the bedside being used. The normal range is four to nine minutes. The kaolin-activated partial th.romboplastin time (normal range 30 to 45 seconds) and plasma heparin assay were performed on citrated samples of plasma collected at the same time as the coagulation time test. For the purpose of dose adjustment, a whole-blood coagulation time between 15 and 25 minutes and a plasma heparin concentration ranging from 0.5 to 1.5 units $/ \mathrm{ml}$. were considered desirable. No limits were set on the results of the partial thromboplastin time.

\section{Results}

\section{Correlation between Laboratory Tests}

There were positive correlations between the results of the three tests, but these were not close (Figs. 1-3). The correlation coefficient $\mathbf{r}$ between the results of whole-blood coagulation time and activated partial thromboplastin time of plasma (Fig. 1) was 0.6009. A whole-blood coagulation time between 15 and 25 minutes was, however, associated with a range of partial thromboplastin times of 50 to more than 300 seconds 